\title{
Co-existence of lung carcinoma metastasis and enchondroma in the femur of a patient with Ollier disease
}

\author{
Xudong Wang ${ }^{1}$ - Xiaohui Zhang ${ }^{2} \cdot$ Wenling $\operatorname{Pan}^{3} \cdot$ Yuedong Han ${ }^{4} \cdot$ Yanwei $\mathrm{Li}^{1} \cdot$ Haibin Sun ${ }^{1}$. \\ Pancras C. W. Hogendoorn ${ }^{5}$ (D) $\cdot$ Hong Cheng ${ }^{1}$ (D)
}

Received: 24 August 2020 / Revised: 13 September 2020 / Accepted: 22 September 2020 / Published online: 13 October 2020

(C) The Author(s) 2020

\begin{abstract}
Tumour-to-tumour metastasis is very unusual and has been defined as a tumour metastasis into another histologically different tumour. It is extremely rare in bone. We report a case of lung squamous cell carcinoma metastasized to an enchondroma in the femur of a patient with Ollier disease. A 60-year-old female had a history of a poorly differentiated squamous cell carcinoma of the lung. She underwent a video-assisted thoracoscopic lobectomy, and a follow-up MRI scan showed three lesions in the left distal femur and proximal tibia, which were initially interpreted as metastasis on radiology. Resection of the left proximal tibial lesion was performed, and the pathological findings were consistent with enchondroma with no evidence of metastasis. Subsequent curettage of lesions in the distal left femur revealed metastatic poorly differentiated carcinoma with foci of hyaline cartilage, which was most consistent with metastatic carcinoma in a pre-existing enchondroma. The MRI films were re-reviewed. Characteristic MRI features of enchondroma were found in the lesion in the left proximal tibia and one of the lesions in the left distal femur, while the features of the other lesion in the left distal femur included cortical destruction and extensive oedema in surrounding soft tissue, which were consistent with a malignant tumour. In addition, the enchondroma in the lateral condyle showed blurring and irregular inner margin and adjacent bone oedema, which likely represents a co-existing metastatic tumour and enchondroma. The difference in lineage was confirmed by immunohistochemistry. The final diagnosis was metastatic poorly differentiated carcinoma of the lung into a co-existent enchondroma. The diagnosis can be challenging and could be easily overlooked both radiologically and histologically. Thorough clinical and radiological information is critical for the diagnosis, and despite a very unusual event, awareness of the tumour-to-tumour metastasis phenomenon can avoid an inaccurate diagnosis by the pathologist, therefore preventing inappropriate clinical intervention.
\end{abstract}

Keywords Bone tumour · Ollier disease $\cdot$ Tumour-to-tumour metastasis $\cdot$ Lung carcinoma $\cdot$ Enchondroma

Pancras C. W. Hogendoorn

p.c.w.hogendoorn@lumc.nl

Hong Cheng

chenghongfmmu85@yahoo.com

1 Department of Pathology, The Fifth Affiliated Hospital of Zhengzhou University, Zhengzhou, Henan Province, China

2 Department of Pathology, H. Lee Moffitt Cancer Center and Research Institute, Tampa, FL, USA

3 Department of Radiology, The Fifth Affiliated Hospital of Zhengzhou University, Zhengzhou, Henan Province, China

4 Department of Radiology, GaoXin Hospital, Xi'an Jiao Tong University, No.16, South Tuanjie Road, Xi'an, Shaanxi, China

5 Department of Pathology, Leiden University Medical Center, Leiden, The Netherlands

\section{Background}

Tumour-to-tumour metastasis is a rare phenomenon that has been described as an occurrence of distant tumour metastasis into another histologically different tumour. The metastatic tumour is usually an aggressive high-grade neoplasm, while the primary tumour is often a more indolent one. Although tumour-to-tumour metastasis cases have been reported intermittently, it is extremely rare in the bone. We herein present a case of a patient with Ollier disease with multiple enchondroma [1] and within an enchondroma in the femur a tumour-to-tumour metastasis from a lung squamous cell carcinoma. To our knowledge, this report is the first case of tumour-to-tumour metastasis from a lung carcinoma to an enchondroma in the context of Ollier disease. 


\section{Case report}

A 60-year-old female was admitted to our hospital, complaining of cough and expectoration for 2 weeks. A contrast-enhanced computed tomography (CT) scan of the chest revealed a mass with an irregular margin in the posterior segment of the right upper lobe of the lung (Fig. 1a). CTguided percutaneous needle biopsy of the lung was consistent with a diagnosis of poorly differentiated squamous cell carcinoma. The patient underwent a video-assisted thoracoscopic lobectomy. Grossly, the lung lobe measured $16.0 \times 12.0 \times$ $5.0 \mathrm{~cm}$, and the cut section reveals a tan tumour. The tumour was located near the hilum of the lung and measured $5.0 \times$ $4.5 \times 3.5 \mathrm{~cm}$ in dimension. Histological examination revealed a poorly differentiated squamous cell carcinoma with necrosis and brisk mitotic activity (Fig. 2a).

Nearly 4 months after the surgery, the patient was admitted to our hospital for the second time, complaining of swelling, pain and loss of range of movement in the left knee joint. Magnetic resonance imaging (MRI) scan revealed tumours in the left distal femur and the left proximal tibia, which were initially radiologically interpreted as tumour metastasis (Fig. 1d-f). Resection of the left proximal tibial lesion and bone grafting was performed. The pathological diagnosis was enchondroma (Fig. 2b).
Since there was a concern of metastatic carcinoma based on radiological findings, curettage of distal left femoral lesion and bone grafting were performed as well. Grossly, the resected specimen was grey-brown fragments measuring $2.2 \times 1.5 \times 0.8 \mathrm{~cm}$ in toto. On microscopic examination, there were sheets of large polygonal malignant cells with pink or clear cytoplasm, vacuolated nuclei and prominent nucleoli. The tumour infiltrated into bony trabeculae with focal haemorrhage and necrosis. The differential diagnosis on morphology was dedifferentiated chondrosarcoma (ex enchondroma in Ollier disease) or a metastatic carcinoma towards a pre-existing enchondroma. Histologically, it was consistent with metastatic squamous cell carcinoma, but the additional cartilaginous component was puzzling. Interestingly, scattered foci of hyaline cartilage were also in the metastatic carcinoma in a mixed growth pattern (Figs. 2c, d). Some of the cartilaginous lobules were surrounded by osteoid tissue. Pathologically, the cartilage components were most consistent with a pre-existing enchondroma in metastatic carcinoma. Immunohistochemical stains were performed. The tumour cells in the epithelial component were positive for AE1/AE3, CEA, CK5/6, P40 and CK7 and negative for TTF-1 and GATA3. Immunohistochemistry for IDH1 R132H antibody was performed in the tumours of
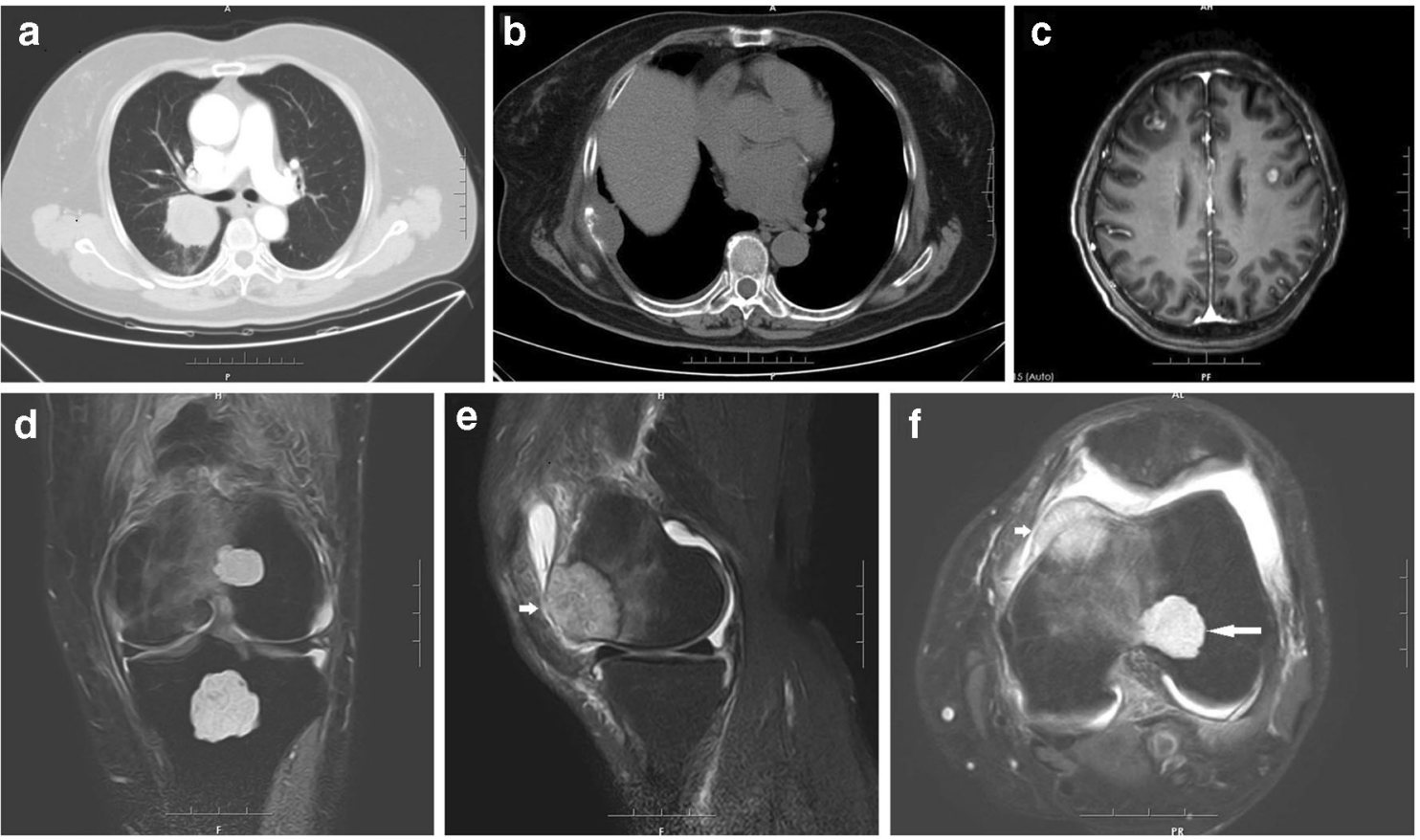

Fig. 1 a Contrast-enhanced CT scan of the chest revealed a mass with irregular margin in the posterior segment of the right upper lobe of the lung. b Osteolytic metastasis in the right 7 th rib with soft tissue mass formation. c Contrast-enhanced MRI image of the brain showed multiple metastases in the bilateral frontal lobes. d-f Coronal (d), sagittal (e) and axial (f) fat-suppressed T2-weighted MRI images demonstrated three lesions in the left femur and tibia, including a lesion in the tibia, a lesion in the anterior part of the medial condyle of femur (short arrow, metastatic carcinoma) and a lesion located in the lateral condyle (long arrow, coexisting tumour of metastasis and enchondroma) 


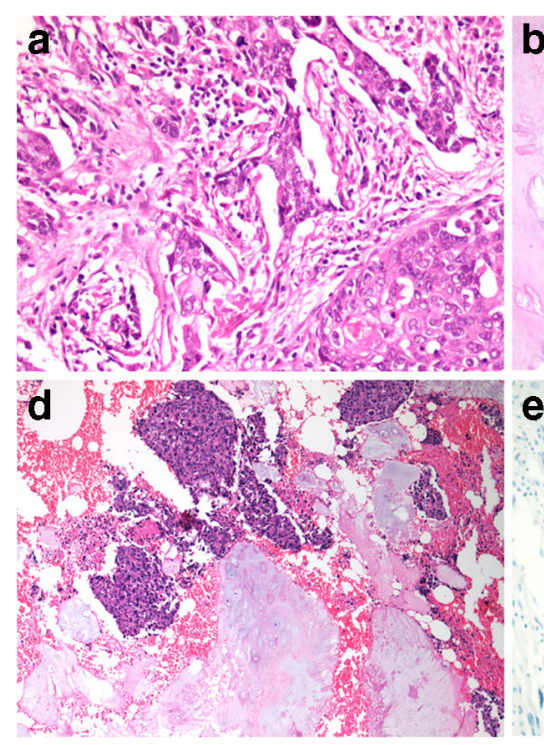

Fig. 2 a Thoracoscopic lobectomy from the right upper lobe of the lung revealed poorly differentiated squamous cell carcinoma. b The tumour from the left proximal tibia was consistent with enchondroma without metastatic component. c, $\mathbf{d}$ Resection from the left distal femur revealed metastatic poorly differentiated carcinoma and foci of hyaline cartilage was present in the metastatic carcinoma, consistent with a metastatic

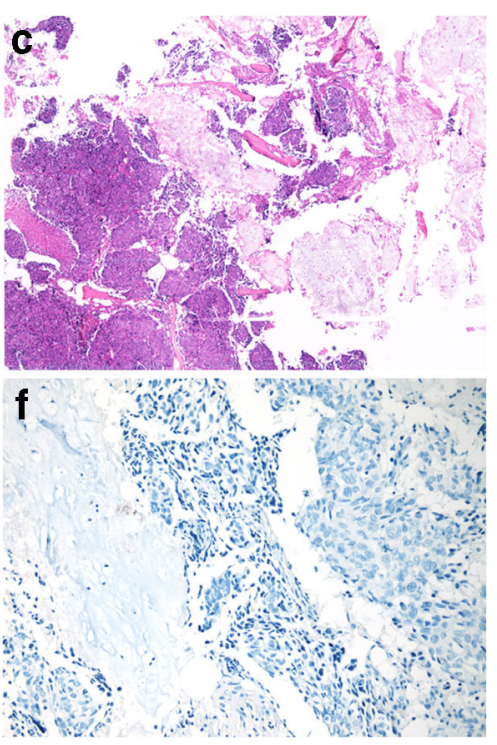

carcinoma in a pre-existing enchondroma. e Immunohistochemical stain for IDH1 was positive in the hyaline cartilage cells but negative in the squamous cell carcinoma cells in lung. f Immunohistochemical stain for IDH1 was weakly positive in the enchondroma cells but negative in the metastatic squamous cell carcinoma cells

Approximately 200 tumour-to-tumour metastasis cases have been reported since 1902 [5]. Berent first reported a case of metastatic squamous cell carcinoma from the jaw into renal cell carcinoma [6]. Fried in 1930 presented a case of bronchogenic carcinoma metastasizing into a meningioma [7]. Since then, various tumour-to-tumour metastasis case reports and series have been reported in the literature [8-12]. Based on the literature review, the most frequent metastatic donor is lung carcinoma, while renal cell carcinoma and meningioma are the most frequent malignant and benign recipients, respectively [5]. Campbell et al. [13] in 1968 reviewed previously published cases and proposed criteria to define tumour-totumour metastasis as follows: more than one distinctly separated primary tumours exist with the recipient tumour being a true neoplasm; the donor neoplasm must be a true metastasis with exclusion of tumour emboli or direct invasion from an adjacent tumour; exclude tumours that have metastasized to the lymphatic system.

In the present case, the first radiographic presentation of the patient was a pulmonary mass, which was pathologically diagnosed as a poorly differentiated squamous cell carcinoma of the lung. The follow-up MRI scan showed multiple lesions in the left femur and tibia, which were initially radiologically interpreted as metastasis, but pathologic examination revealed a diagnosis of enchondroma for left proximal tibial lesion and metastatic lung carcinoma and co-existent enchondroma for the distal left femoral lesion. Subsequent re-review of the MRI image confirmed that the left proximal tibial lesion and one of the lesions in the distal left femur were enchondromas, while reported previously [4]. 
the other distal femoral lesion was a malignant tumour partially "melting" with the enchondroma.

In this case, with the presence of both benign cartilaginous and high-grade malignant non-cartilaginous components, a differential diagnosis would be dedifferentiated chondrosarcoma. According to the latest WHO classification of bone tumours [14], the low-grade cartilaginous component can range from enchondroma-like appearance to grade 1 or grade 2 chondrosarcoma. The expression of keratin in the high-grade component cannot exclude dedifferentiated chondrosarcoma. Although the high-grade component almost always exhibits mesenchymal differentiation, it has been reported that rare cases of dedifferentiated chondrosarcoma can show epithelial differentiation, including squamous, glandular or adamantinoma-like features [15-19]. In such cases, detection of IDH1/2 gene mutations may be helpful in the diagnosis, which has been demonstrated in both high- grade and low-grade chondrosarcoma [20-22]. The positive IDH1 staining in the cartilaginous tumour and the negative staining in the poorly differentiated parts support the diagnosis of metastatic carcinoma as in dedifferentiated chondrosarcoma the IDH1 mutations persist [20].

Based on the literature, metastases to a benign tumour are more common than those to malignant tumours. A few factors have been proposed to explain the reason. The most reasonable one may be the benign tumour's slow growth rate with low metabolic activity, which can provide prolonged exposure and a non-competitive environment for metastatic seeding and growth [23, 24]. These features are consistent with an enchondroma.

Bone metastases are common in practice, while the coexistence of metastases with benign or malignant primary bone neoplasms is rare in the literature. To our best knowledge, this is the first report of a lung carcinoma metastasizing to an enchondroma of a patient with Ollier disease. The diagnosis of metastatic carcinoma in a primary bone tumour can be challenging. It can be easily overlooked both radiologically and pathologically, which may lead to misdiagnosing a benign bone tumour as malignant tumour or mislabelling the metastatic carcinoma as dedifferentiated chondrosarcoma. Thorough clinical and radiological information is critical for an accurate diagnosis. Awareness of the tumour-to-tumour metastasis phenomenon by the pathologist can prevent inappropriate clinical intervention.

Authors' contributions XW put together the material of the case and wrote the first draft of the manuscript; XZ was responsible for revising the manuscript; WP supplied the CT and enhanced CT image information; $\mathrm{YH}$ reviewed and described the radiological material; YL produced all histological and immunohistochemical stainings; HS participated in writing of the manuscript; $\mathrm{PH}$ reviewed the case in consultation and was involved in extra immunohistochemical staining to confirm the diagnosis; $\mathrm{HC}$ was involved in the pathology diagnosis and supervised the reporting process of the case. All authors have read, commented, and approved the final manuscript.

\section{Compliance with ethical standards}

Conflict of interest The authors declare that they have no conflict of interest.

Ethics Because fully anonymized pathology material and reports as well as radiology material and reports were used, and as it is a case report of a one-time clinical event, no informed consent was obtained. This is according to the author's institutes ethical guidelines.

Open Access This article is licensed under a Creative Commons Attribution 4.0 International License, which permits use, sharing, adaptation, distribution and reproduction in any medium or format, as long as you give appropriate credit to the original author(s) and the source, provide a link to the Creative Commons licence, and indicate if changes were made. The images or other third party material in this article are included in the article's Creative Commons licence, unless indicated otherwise in a credit line to the material. If material is not included in the article's Creative Commons licence and your intended use is not permitted by statutory regulation or exceeds the permitted use, you will need to obtain permission directly from the copyright holder. To view a copy of this licence, visit http://creativecommons.org/licenses/by/4.0/.

\section{References}

1. Verdegaal SH, Bovee JV, Pansuriya TC, Grimer RJ, Ozger H, Jutte PC, San Julian M, Biau DJ, van der Geest IC, Leithner A, Streitburger A, Klenke FM, Gouin FG, Campanacci DA, MarecBerard P, Hogendoorn PC, Brand R, Taminiau AH (2011) Incidence, predictive factors, and prognosis of chondrosarcoma in patients with Ollier disease and Maffucci syndrome: an international multicenter study of 161 patients. Oncologist 16(12):1771-1779. https://doi.org/10.1634/theoncologist.2011-0200

2. Geirnaerdt MJ, Bloem JL, Eulderink F, Hogendoorn PC, Taminiau AH (1993) Cartilaginous tumours: correlation of gadoliniumenhanced MR imaging and histopathologic findings. Radiology 186(3):813-817. https://doi.org/10.1148/radiology.186.3.8430192

3. Piccioli A, Maccauro G, Spinelli MS, Biagini R, Rossi B (2015) Bone metastases of unknown origin: epidemiology and principles of management. J Orthop Traumatol 16(2):81-86. https://doi.org/ 10.1007/s10195-015-0344-0

4. Aycan OE, Sebastiani E, Bianchi G, Gambarotti M (2019) Coexistence of secondary chondrosarcoma and lung carcinoma metastasis in the humerus of a patient with Ollier's disease: a case report. Acta Orthop Traumatol Turc 53(1):68-73. https://doi.org/ 10.1016/j.aott.2018.10.008

5. Yano M, Katoh T, Hamaguchi T, Kozawa E, Hamada M, Nagata K, Yasuda M (2019) Tumour-to-tumour metastasis from appendiceal adenocarcinoma to an ovarian mature teratoma, mimicking malignant transformation of a teratoma: a case report. Diagn Pathol 14(1):88. https://doi.org/10.1186/s13000-019-0865-6

6. Lowenthal BM, Fadare O (2017) The rare phenomenon of tumourto-tumour metastasis. Int J Surg Pathol 25(1):63-64. https://doi.org/ $10.1177 / 1066896916668032$

7. Fried BM (1930) Metastatic inoculation of a meningioma by cancer cells from a bronchiogenic carcinoma. Am J Pathol 6(1):47-52 41

8. Cohn ML, Elliott DD, El-Naggar AK (2005) Metastatic acinic cell carcinoma in a neurofibroma mistaken for carcinosarcoma. Head Neck 27(1):76-80. https://doi.org/10.1002/hed.20133 
9. Moody P, Murtagh K, Piduru S, Brem S, Murtagh R, Rojiani AM (2012) Tumour-to-tumour metastasis: pathology and neuroimaging considerations. Int J Clin Exp Pathol 5(4):367-373

10. Sakai Y, Kanomata N, Itami H, Kajimoto K, Sakuma T, Ohbayashi C (2010) Signet-ring cell carcinoma of the stomach metastasizing to renal cell carcinoma: a case report and review of the literature. Kobe J Med Sci 55(6):E122-E131

11. Tan W, Tao L, Zhou Z, Yin W, Chen Y (2019) Tumour-to-tumour metastasis: a rare case of breast carcinoma metastasizing to a pheochromocytoma, and a literature review. Diagn Pathol 14(1):46. https://doi.org/10.1186/s13000-019-0816-2

12. Twaalfhoven FC, Fleuren GJ, Cornelisse CJ, Peters AA, Trimbos JB, Hogendoorn PC (1994) Metastasis of breast carcinoma to a primary mucinous cystadenocarcinoma of the ovary. Gynecol Oncol 52(1):80-86. https://doi.org/10.1006/gyno.1994.1015

13. Campbell LV Jr, Gilbert E, Chamberlain CR Jr, Watne AL (1968) Metastases of cancer to cancer. Cancer 22(3):635-643. https://doi. org/10.1002/1097-0142(196809)22:3<635::aid cncr2820220320>3.0.co;2-o

14. Inwards CY, Bloem JL, Hogendoorn PCW. Dedifferentiated chondrosarcoma. In WHO Classification of Tumours Editorial Board (2020) Soft tissue and bone tumours. World Health Organization, pp 388-390

15. Gambarotti M, Righi A, Frisoni T, Donati D, Vanel D, Sbaraglia M, Dei Tos AP (2017) Dedifferentiated chondrosarcoma with "adamantinoma-like" features: a case report and review of literature. Pathol Res Pract 213(6):698-701. https://doi.org/10.1016/j. prp.2017.04.019

16. Jour G, Liu Y, Ricciotti R, Pritchard C, Hoch BL (2015) Glandular differentiation in dedifferentiated chondrosarcoma: molecular evidence of a rare phenomenon. Hum Pathol 46(9):1398-1404. https:// doi.org/10.1016/j.humpath.2015.05.018

17. Ling LL, Steiner GC (1986) Primary multipotential malignant neoplasm of bone: chondrosarcoma associated with squamous cell carcinoma. Hum Pathol 17(3):317-320. https://doi.org/10.1016/ s0046-8177(83)80227-5

18. Shiraishi J, Mukai M, Yabe H, Shibata R, Yamada T, Miura K, Anazawa U, Morioka H, Sakamoto M (2005) Primary bone carcinosarcoma: chondrosarcoma and squamous cell carcinoma with keratin pearl formation. Pathol Int 55(8):504-509. https://doi. org/10.1111/j.1440-1827.2005.01860.x

19. Zhang Y, Paz Mejia A, Temple HT, Trent J, Rosenberg AE (2014) Squamous cell carcinoma arising in dedifferentiated chondrosarcoma proved by isocitrate dehydrogenase mutation analysis. Hum Pathol 45(7):1541-1545. https://doi.org/10.1016/j. humpath.2014.02.016

20. Amary MF, Bacsi K, Maggiani F, Damato S, Halai D, Berisha F, Pollock R, O'Donnell P, Grigoriadis A, Diss T, Eskandarpour M, Presneau N, Hogendoorn PC, Futreal A, Tirabosco R, Flanagan AM (2011) IDH1 and IDH2 mutations are frequent events in central chondrosarcoma and central and periosteal chondromas but not in other mesenchymal tumours. J Pathol 224(3):334-343. https://doi. org/10.1002/path.2913

21. Bovee JV, Cleton-Jansen AM, Rosenberg C, Taminiau AH, Cornelisse CJ, Hogendoorn PC (1999) Molecular genetic characterization of both components of a dedifferentiated chondrosarcoma, with implications for its histogenesis. J Pathol 189(4):454-462. https://doi.org/10.1002/(SICI)10969896(199912)189:4<454::AID-PATH467>3.0.CO;2-N

22. Ropke M, Boltze C, Neumann HW, Roessner A, Schneider-Stock $\mathrm{R}$ (2003) Genetic and epigenetic alterations in tumour progression in a dedifferentiated chondrosarcoma. Pathol Res Pract 199(6):437444. https://doi.org/10.1078/0344-0338-00443

23. Glass R, Hukku SR, Gershenhorn B, Alzate J, Tan B (2013) Metastasis of lung adenosquamous carcinoma to meningioma: case report with literature review. Int J Clin Exp Pathol 6(11):26252630

24. Richardson JF, Katayama I (1971) Neoplasm to neoplasm metastasis. An acidophil adenoma harbouring metastatic carcinoma: a case report. Arch Pathol 91(2):135-139

Publisher's note Springer Nature remains neutral with regard to jurisdictional claims in published maps and institutional affiliations. 